medRxiv preprint doi: https://doi.org/10.1101/2021.03.25.21254087; this version posted March 26, 2021. The copyright holder for this preprint (which was not certified by peer review) is the author/funder, who has granted medRxiv a license to display the preprint in It is made available under a CC-BY 4.0 International license.

\title{
Prenatal smoking, alcohol and caffeine exposure and ADHD risk in childhood: parental comparisons and polygenic risk score (PRS) analyses
}

Elis Haan ${ }^{1,2}$, Hannah M. Sallis ${ }^{1,2}$, Luisa Zuccolo ${ }^{2,3}$, Jeremy Labrecque ${ }^{4}$, Eivind Ystrom ${ }^{5,6,7}$, Ted

Reichborn-Kjennerud ${ }^{6,8}$, Ole Andreassen ${ }^{9}$, Alexandra Havdahl ${ }^{5,6,10^{*}}$, Marcus R. Munafò ${ }^{1,2^{*}}$

1 School of Psychological Science, University of Bristol, Bristol, UK

2 MRC Integrative Epidemiology Unit at the University of Bristol, Bristol, UK

3 Department of Population Health Sciences, Bristol Medical School, University of Bristol, Bristol, UK

4 Department of Epidemiology, Erasmus MC, Rotterdam, the Netherlands

5 PROMENTA Research Center, Department of Psychology, University of Oslo, Oslo, Norway

6 Department of Mental Disorders, Norwegian Institute of Public Health, Oslo, Norway

7 School of Pharmacy, University of Oslo, Oslo, Norway

8 Institute of Clinical Medicine, University of Oslo, Oslo, Norway

9 NORMENT Centre, Institute of Clinical Medicine, University of Oslo, and Division of Mental Health and Addiction, Oslo University Hospital, Oslo, Norway

10 Nic Waals Institute, Lovisenberg Diaconal Hospital, Oslo, Norway

*co-senior authors

CORRESPONDING AUTHOR: Elis Haan

NOTE: This preprint reports new research that has not been certified by peer review and should not be used to guide clinical practice. 
medRxiv preprint doi: https://doi.org/10.1101/2021.03.25.21254087; this version posted March 26, 2021. The copyright holder for this preprint (which was not certified by peer review) is the author/funder, who has granted medRxiv a license to display the preprint in It is made available under a CC-BY 4.0 International license.

\begin{abstract}
Background and aims: Several studies have indicated that maternal prenatal substance use may be associated with offspring ADHD via intrauterine effects. We investigated associations between maternal prenatal smoking, alcohol and caffeine consumption with childhood ADHD risk accounting for shared familial factors.

Design: First, we used a negative control design comparing maternal and paternal substance use. Three models were used for negative control analyses: unadjusted (without confounders); adjusted (including confounders) and mutually adjusted (including confounders and partner's substance use). The results were meta-analysed across the cohorts. Second, we used polygenic risk scores (PRS) as proxies for exposures. Maternal PRS for genetic variants of smoking, alcohol and coffee consumption were regressed against ADHD risk. We triangulated the results across the two approaches to infer causality.
\end{abstract}

Setting: We used data from three longitudinal pregnancy cohorts: Avon Longitudinal Study of Parents and Children (ALSPAC) in the UK, Generation R study (GenR) in the Netherlands and Norwegian Mother, Father and Child Cohort study (MoBa) in Norway.

Participants: Phenotype data available for children was: $\mathrm{N}_{\mathrm{ALSPAC}}=7,850 ; \mathrm{N}_{\mathrm{GENR}}=3,849 ; \mathrm{N}_{\mathrm{MOBA}}=43,512$. Genotype data available for mothers was: $\mathrm{N}_{\mathrm{ALSPAC}}=7,074$ and $\mathrm{N}_{\mathrm{MOBA}}=14,583$.

Measurements: Offspring ADHD risk around age 7-8 was derived by dichotomising symptom scores from multiple questionnaires and parental self-reported substance use was measured at the $2^{\text {nd }}$ pregnancy trimester.

Findings: The pooled estimate for maternal prenatal substance use showed an association with $\mathrm{ADHD}$ risk $\left(\mathrm{OR}_{\mathrm{SMOKING}}=1.11,95 \% \mathrm{Cl} 1.00-1.23 ; \mathrm{OR}_{\mathrm{ALCOHOL}}=1.27,95 \% \mathrm{Cl} 1.08-1.49 ; \mathrm{OR}_{\text {CAFFEINE }}=1.05,95 \% \mathrm{Cl}\right.$ 1.00-1.11), while not for fathers $\left(\mathrm{OR}_{\mathrm{SMOKING}}=1.03,95 \% \mathrm{Cl} 0.95-1.13 ; \mathrm{OR}_{\mathrm{ALCOHOL}}=0.83,95 \% \mathrm{Cl} 0.47-1.48\right.$; $\mathrm{OR}_{\text {CAFFEINE }}=1.02,95 \% \mathrm{Cl}$ 0.97-1.07). However, maternal associations did not persist in sensitivity analyses (substance use before pregnancy, adjustment for maternal ADHD in MoBa). The PRS analyses did not show evidence of association in ALSPAC or MoBa.

Conclusions: Our results do not provide support for a causal intrauterine effect of maternal prenatal substance use on offspring attention-deficit hyperactivity disorder risk.

Keywords: smoking, alcohol, caffeine, polygenic risk score, negative control, mental health, intrauterine effects, ALSPAC, GenR, MoBa 
medRxiv preprint doi: https://doi.org/10.1101/2021.03.25.21254087; this version posted March 26, 2021. The copyright holder for this

preprint (which was not certified by peer review) is the author/funder, who has granted medRxiv a license to display the preprint in

perpetuity.
It is made available under a CC-BY 4.0 International license .

\section{Introduction}

Many observational studies have shown that symptoms and diagnosis of attention deficit hyperactivity disorder (ADHD) are associated with maternal prenatal smoking $(1,2)$ and mixed findings have been reported for association with prenatal alcohol and caffeine exposure (3-8). However, inferring causality from associations between maternal prenatal substance use and offspring ADHD is challenging because the association could be affected by unmeasured shared familial factors that contribute to both maternal prenatal substance use and offspring ADHD. Several studies have shown genetic overlap between substance use and ADHD (9), and maternal genetic risk for ADHD has been associated with smoking during pregnancy (10).

Negative control designs (i.e. parental and sibling comparison) have been used to investigate potential causal intrauterine effects for a range of outcomes $(11,12)$. The main principle of the negative control approach is to compare the association of interest with another related association which is not biologically plausible (11). For example, in a parental comparison, if the maternal exposure-child outcome association is stronger, compared with the paternal exposure-child outcome association, this would suggest a potentially causal intrauterine effect. In contrast, if the magnitude of association is similar, this would argue against a causal intrauterine effect, and instead suggest the association is due to confounding.

Negative control designs have been used in the context of maternal prenatal substance use and offspring ADHD. A study based on the Danish National Birth Cohort using parental comparison found evidence for a potential causal association between maternal prenatal smoking and offspring ADHD (13). However, several other studies using negative control and other genetically sensitive designs have concluded that the association between maternal prenatal smoking and offspring ADHD is likely not causal $(14,15)$. Sibling comparison studies on alcohol exposure based on the Norwegian Mother, Father and Child Cohort Study (MoBa) have found little evidence for a causal association with ADHD diagnosis $(16,17)$ although a sibling control analysis $(16)$ suggested some evidence for a potential causal association with ADHD symptoms as measured by the Conner's Parent Rating Scale (CPRS-R). To our knowledge no negative control studies have been published on prenatal caffeine exposure and offspring ADHD.

Although published negative control studies investigating intrauterine effects have improved our knowledge of causal effects, they may still be biased because of unmeasured and residual 
medRxiv preprint doi: https://doi.org/10.1101/2021.03.25.21254087; this version posted March 26, 2021. The copyright holder for this preprint (which was not certified by peer review) is the author/funder, who has granted medRxiv a license to display the preprint in perpetuity.
It is made available under a CC-BY 4.0 International license.

confounding. Using genetic variants in Mendelian randomization (MR) analyses is an alternative approach that can strengthen causal inference when using observational data. Genetic variants are randomly and independently assigned at conception and should therefore not be associated with factors that normally confound the exposure-outcome relationship. They can therefore provide stronger support for a potential causal association (18). However, studies using genetic variants (i.e polygenic risk score (PRS)) and MR rely on three main assumptions: (1) relevance - the genetic variant must be robustly associated with the exposure of interest; (2) independence - the genetic variant is not confounded with the outcome or related through selection bias and (3) exclusion restriction - the genetic variant is not associated with the outcome by any other path than through the exposure of interest (19). Assumptions 2 and 3 cannot be tested and, therefore, problems with horizontal pleiotropy - where the same genetic variant is directly associated with many phenotypes confounding of genetic variant's relationship with the outcome or selection bias cannot be ruled out (18).

Combining multiple methodological approaches that rely on different assumptions and are subject to different sources of bias - known as triangulation - can strengthen causal inference (20). If results from multiple approaches provide convergent results, it is more likely that the observed association reflects a causal effect (21). In the present study we combined the conventional multivariable regression approach, a negative control design using paternal prenatal substance use as a negative control for the intrauterine exposure, and genetic analyses using PRS as a proxy for the exposures of interest. Our aim was to investigate whether there is a causal effect of maternal prenatal substance use on offspring ADHD outcomes at age 7-8 (Figure 1), using data from three large prospective birth cohorts.

Insert Figure 1 here. 
medRxiv preprint doi: https://doi.org/10.1101/2021.03.25.21254087; this version posted March 26, 2021. The copyright holder for this preprint (which was not certified by peer review) is the author/funder, who has granted medRxiv a license to display the preprint in

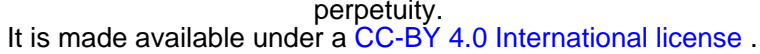

\section{Methods}

\section{Study populations}

We used data from three European prospective longitudinal birth cohorts: the Avon Longitudinal Study of Parents and Children (ALSPAC), Generation R (GenR) and the Norwegian Mother, Father and Child Cohort Study (MoBa). ALSPAC is a prospective longitudinal cohort study that recruited 14,541 pregnant women resident in Avon, UK with expected dates of delivery between 1st April 1991 and 31st December 1992 (22-24). GenR is a population-based prospective cohort study in Rotterdam in the Netherlands that recruited 9,778 pregnant women expected to give birth between April 2002 and January 2006 (25). MoBa is a population-based pregnancy cohort study where participants were recruited from all over Norway between 1999 and 2008. The cohort now includes 114,500 children, 95,200 mothers and 75,200 fathers (26). More details are shown in the Supplementary Material.

\section{Genome-wide genotype data}

In ALSPAC, genome-wide data were available for 8,196 mothers. Maternal genetic data was not available for GenR at the time of analyses. In MoBa, genetic data were available for 14,584 mothers. Detailed information about the genotyping is presented in the Supplementary Material.

\section{Exposures}

We used data assessed in the $2^{\text {nd }}$ pregnancy trimester where information for both maternal and paternal substance use was available. Briefly, mothers and fathers were asked about their average number of cigarettes smoked per day if they were smokers, average amount and frequency of alcohol consumption, and how many cups of caffeinated drinks (coffee, tea, cans of cola) per day on average they consumed during the first pregnancy trimester and mothers also before pregnancy. Overall, exposure assessment was similar across the cohorts, but there were some exceptions in GenR (Supplementary Table S1).

Parental prenatal smoking, alcohol and caffeine consumption (from coffee and tea) were categorized to examine dose-dependent relationships. Smoking was categorized: No smoking; 1-4 cigarettes; 5-9 cigarettes and $>10$ cigarettes per day. Alcohol consumption was categorized: No drinking; $<1$ drink a week and 1-6 drinks a week. Only a small number of mothers drank daily, therefore these were combined with the group of weekly drinkers. Furthermore, because the measure of alcohol unit was different in each cohort, meta-analysis across the cohorts was conducted comparing drinkers and non-drinkers. However, in ALSPAC and MoBa we were able to harmonise weekly alcohol consumption from units to grams to create a continuous measure of alcohol consumption 
medRxiv preprint doi: https://doi.org/10.1101/2021.03.25.21254087; this version posted March 26, 2021. The copyright holder for this

preprint (which was not certified by peer review) is the author/funder, who has granted medRxiv a license to display the preprint in

It is made available under a CC-BY 4.0 International license.

(Supplementary Table S1). Caffeine consumption from coffee and tea was transformed and summed to total caffeine consumption in milligrams per day and categorized: 0-49mg; 50-199mg; $200-299 \mathrm{mg}$ and $>300 \mathrm{mg}$.

\section{Outcome}

ADHD symptoms were measured using different questionnaires around age 7-8 years in each cohort. Given that some studies have found that maternal prenatal substance use can have a distinct effect on hyperactivity and inattention symptom domains $(27,28)$, in each cohort we used questionnaires that measured total ADHD symptoms, as well as hyperactivity and inattention symptom domains.

As the continuous score of ADHD symptoms was either zero-inflated or skewed, a binary variable was derived for total ADHD, hyperactivity and inattention symptoms using the $85^{\text {th }}$ percentile threshold to indicate a high risk of ADHD symptoms (29). Up to 4 missing items were allowed depending on number of items in the questionnaire. More details are shown in Supplementary Table S2.

\section{Primary outcome measures:}

The psychometric scales used for the main outcome measure were: maternal report of the Development And Well-Being Assessment (DAWBA) questionnaire in ALSPAC; maternal report of the revised Conner's Parent Rating Scale (CPRS-R) in GenR; and maternal report of the Disruptive Behaviour Disorders scale (RS-DBD) in MoBa.

\section{Secondary outcome measures:}

There is evidence of measurement differences of maternal and teacher reported ADHD symptoms in children (30), and some studies have found conflicting results depending on the questionnaire used (16). We therefore included additional questionnaires: teacher report of the DAWBA questionnaire and maternal and teacher report of the Strength and Difficulties Questionnaire (SDQ) hyperactivity subscale in ALSPAC; and maternal and teacher report of the Child Behaviour Checklist (CBCL) attention problems subscale in GenR.

\section{Polygenic risk scores}

PRS for mothers in ALSPAC and MoBa were calculated using genome-wide hits $\left(p<5 \times 10^{-8}\right)$ and weighted by effect estimates as reported in recent genome-wide association studies (GWAS) of tobacco, alcohol (31) and coffee consumption (32) using PLINK v1.90. More details about the phenotypes and SNPs discovered in these GWAS are shown in Supplementary Table S3. PRS for smoking heaviness was calculated using 49 single nucleotide polymorphisms (SNPs) available in 
medRxiv preprint doi: https://doi.org/10.1101/2021.03.25.21254087; this version posted March 26, 2021. The copyright holder for this preprint (which was not certified by peer review) is the author/funder, who has granted medRxiv a license to display the preprint in It is made available under a CC-BY 4.0 International license.

ALSPAC and 51 SNPs available in MoBa and the sample was restricted to smokers during pregnancy. PRS for alcohol consumption was calculated with 90 SNPs available in ALSPAC and 92 SNPs available in MoBa and the sample was restricted to mothers who drank during pregnancy. PRS for caffeine consumption was calculated with 8 SNPs available in ALSPAC and 7 SNPs available in MoBa. There was some overlap between the SNPs included in the PRS for alcohol and caffeine, but no overlap between PRS for smoking and alcohol or caffeine. The correlation between these PRS were low (Supplementary Table S4).

\section{Statistical analyses}

All analyses were performed using Stata (v15: ALSPAC, GenR; v16: MoBa), (33, 34). Analyses were performed as described in our pre-registered protocol (35). Analyses were conducted separately in each cohort and results from primary outcome measure (maternal reported ADHD symptoms) were meta-analysed across the cohorts using a random effects model. This model takes into account the variance in the exposure and outcome assessment across the cohorts. The sample in each cohort was restricted to singletons in ALSPAC and GenR, whereas in MoBa a robust cluster variance estimator was used to account for the presence of siblings. In ALSPAC and GenR paternal analyses were restricted to individuals who were reported as biological fathers. An overview of the analysis sample is shown in Table 1.

\section{Insert Table1 here.}

Negative control analyses:

Associations between maternal and paternal (negative control) exposures and offspring ADHD risk were tested using logistic regression analyses. We used three models: unadjusted (without including potential confounders); adjusted (for confounders identified based on previous studies (36-40): child's gender, ethnicity, parental age, education, depression and anxiety problems, financial difficulties, marital status and smoking, alcohol and caffeine use) and mutually adjusted (adjusted for confounders and for partner's substance use). Mutually adjusted models account for assortative mating, and there is evidence of this for health behaviours such as smoking and alcohol use $(12,41$ 43). In MoBa, because of the longer recruitment period, analyses were additionally adjusted for birth year.

\section{PRS analyses:}

We investigated the association between: 1) maternal PRS and maternal exposure phenotypes to validate the PRS during pregnancy; 2) with offspring ADHD risk. PRS analyses in ALSPAC and MoBa 
medRxiv preprint doi: https://doi.org/10.1101/2021.03.25.21254087; this version posted March 26, 2021. The copyright holder for this

preprint (which was not certified by peer review) is the author/funder, who has granted medRxiv a license to display the preprint in

It is made available under a CC-BY 4.0 International license.

were performed with adjustment for 10 ancestry-informative principal components. In MoBa, PRS analyses were additionally adjusted for birth year and genotyping batch. To explore potential pleiotropic effects, we also tested the association between the PRS and each confounder included in the negative control analysis.

\section{$\underline{\text { Sensitivity analyses }}$}

Negative control analyses:

If an association was observed between maternal prenatal substance use and offspring ADHD risk, we further tested our hypothesis of a potential intrauterine effect by comparing maternal prenatal substance use with substance use before pregnancy. Given that ADHD is highly heritable, it is plausible that any observed associations between maternal PRS and offspring ADHD risk could be explained by genetic transmission. In MoBa, a measure of maternal ADHD symptoms was available, enabling us to test whether maternal ADHD symptoms could explain the observed associations between maternal substance use and offspring ADHD risk. Finally, we also performed analyses with complete cases by restricting unadjusted and adjusted analyses to the sample in the mutually adjusted model for each exposure.

\section{PRS analyses:}

Unweighted PRS were calculated to test the association with each exposure phenotype, given that SNPs selected based only on the genome-wide significance level may be biased upwards (the socalled Winner's Curse) (44). In addition to the PRS for smoking heaviness, we included a PRS for lifetime smoking, which captures smoking initiation, duration, heaviness and cessation, and can be used without stratifying samples on smoking status (45). The GWAS of lifetime smoking identified 126 independent SNPs at the genome-wide level of significance $\left(p<5 \times 10^{-8}\right)$, of which 123 were available in ALSPAC and 121 in MoBa. Finally, given that longitudinal studies may be subject to selection bias (46), we tested associations between PRS for smoking, alcohol and caffeine use and whether mothers returned the questionnaire at child age 7-8 in ALSPAC and MoBa. 
medRxiv preprint doi: https://doi.org/10.1101/2021.03.25.21254087; this version posted March 26, 2021. The copyright holder for this preprint (which was not certified by peer review) is the author/funder, who has granted medRxiv a license to display the preprint in It is made available under a CC-BY 4.0 International license.

\section{Results}

Overall, the negative control analyses comparing maternal and paternal substance use associations with offspring ADHD risk showed mixed results across the cohorts. Stronger maternal associations were observed in MoBa, where mothers had lower prenatal smoking, alcohol and caffeine consumption compared to mothers in ALSPAC and GenR. The results of the meta-analysis are shown in Figure 2. In contrast to the negative control analyses, our PRS analyses in ALSPAC and MoBa did not provide clear evidence for a causal effect of maternal prenatal substance use on offspring ADHD risk. Furthermore, PRS analyses for lifetime smoking indicated pleiotropic associations with sociodemographic and mental health traits, as well as with returning questionnaires.

Insert Figure 2 here.

\section{Smoking}

\section{Negative control analyses}

The pooled estimate for maternal smoking in the mutually adjusted model provided weak evidence of an association with high risk of $A D H D$ total and inattention symptoms $\left(\mathrm{OR}_{\mathrm{ADHD}}=1.11,95 \% \mathrm{Cl} 1.00\right.$, $\left.1.23 ; \mathrm{OR}_{\mathrm{INA}}=1.07,95 \% \mathrm{Cl} 1.01,1.14\right)$. A wide confidence interval was observed for hyperactivity symptoms $\left(\mathrm{OR}_{\mathrm{HYP}}=1.09,95 \% \mathrm{Cl} 0.97,1.23\right)$. For paternal smoking, there was some evidence of an association with high risk of hyperactivity symptoms $\left(\mathrm{OR}_{\mathrm{HYP}}=1.06,95 \% \mathrm{Cl} 1.00,1.11\right)$, but not with other $\mathrm{ADHD}$ outcomes $\left(\mathrm{OR}_{\mathrm{ADHD}}=1.03,95 \% \mathrm{Cl} 0.95,1.13 ; \mathrm{OR}_{\mathrm{INA}}=1.02,95 \% \mathrm{Cl} 0.93,1.11\right)$. The results showing the dose-dependent relationship using non-smoking as baseline across unadjusted, adjusted and mutually adjusted models in each cohort are shown in Supplementary Tables S5-S7.

\section{Sensitivity analyses}

In MoBa, additional adjustment for maternal ADHD symptoms attenuated the association with high risk of offspring ADHD inattention symptoms, but there remained evidence of an association with high risk of ADHD total and hyperactivity symptoms (Supplementary Table S8). Furthermore, there was evidence of an association between maternal smoking before pregnancy and high risk of hyperactivity symptoms (Supplementary Table S9), but the estimates were stronger with smoking during pregnancy.

Analyses using teacher report of DAWBA and SDQ scales in ALSPAC and TRF in GenR found no strong evidence of an association between maternal prenatal smoking and offspring ADHD risk (Supplementary Table S10). In contrast, in GenR there was evidence of an association between 
medRxiv preprint doi: https://doi.org/10.1101/2021.03.25.21254087; this version posted March 26, 2021. The copyright holder for this preprint (which was not certified by peer review) is the author/funder, who has granted medRxiv a license to display the preprint in It is made available under a CC-BY 4.0 International license.

maternal prenatal smoking and high risk of maternal reported ADHD total symptoms measured with CBCL. This association was not observed for maternal smoking before pregnancy (Supplementary Table S11). Results were similar in the analyses with complete cases in each cohort (Supplementary Tables S12-S14).

\section{PRS analyses:}

In each of the PRS analyses we report the results based on the assumptions described in the introduction.

First, the weighted and unweighted PRS for smoking heaviness and lifetime smoking were associated with smoking behaviour in pregnancy in ALSPAC and MoBa (all $p<0.01$ ). These PRS explained $1-3 \%$ of variance in smoking phenotypes in ALSPAC and MoBa (Supplementary Tables S15-S18).

Second, in ALSPAC, we did not find any strong evidence for an association between PRS for smoking heaviness and confounders included in the negative control analyses (Supplementary Table S19). However, in MoBa, we found evidence of an association between the PRS for smoking heaviness and lower parity $(\beta=-0.4195 \% \mathrm{Cl}-0.732,-0.092$; Supplementary Table S20). The PRS for lifetime smoking was associated with younger maternal age $(\beta=-2.64,95 \% \mathrm{Cl}-3.688,-1.586)$, lower education $(\beta=-1.00$, $95 \% \mathrm{Cl}-1.286,-0.711)$, more financial difficulties $(\beta=1.12,95 \% \mathrm{Cl} 0.317,1.912)$, higher likelihood of being single $(\mathrm{OR}=0.24,95 \% \mathrm{Cl} 0.138,0.415)$ and having more severe anxiety symptoms $(\mathrm{OR}=1.98$, $95 \% \mathrm{Cl} 1.035,3.801$ ) in ALSPAC (Supplementary Table S21). Similarly, in MoBa, the PRS for lifetime smoking showed evidence of an association with lower maternal education $(\beta=-0.27,95 \% \mathrm{Cl}-0.356$, 0.191 ) and higher likelihood of having more severe depression and anxiety symptoms (OR=1.98, 95\% Cl 1.052, 3.705; Supplementary Table S22).

Third, in ALSPAC, we did not find strong evidence of an association between the PRS for smoking heaviness and high risk of maternal or teacher reported offspring ADHD symptoms (Supplementary Table S23 \& S24). Similarly, in MoBa, there was no evidence of an association between the PRS for smoking heaviness and offspring ADHD risk (Supplementary Table S25). In contrast, we found no strong evidence of an association between the PRS for lifetime smoking and high risk of maternal reported offspring ADHD symptoms in ALSPAC (Supplementary Table S26), but we did find evidence of an association with high risk of teacher reported ADHD total symptoms measured with both the DAWBA (ORDAWBA $=2.70,95 \% \mathrm{Cl} 1.026,7.079)$ and the SDQ $\left(\mathrm{OR}_{S D Q}=3.00,95 \% \mathrm{Cl} 1.034,8.688\right.$; Supplementary Table S27). There was no strong evidence of an association between maternal PRS for 
medRxiv preprint doi: https://doi.org/10.1101/2021.03.25.21254087; this version posted March 26, 2021. The copyright holder for this preprint (which was not certified by peer review) is the author/funder, who has granted medRxiv a license to display the preprint in It is made available under a CC-BY 4.0 International license.

lifetime smoking and high risk of maternal reported ADHD symptoms in MoBa (Supplementary Table S28).

\section{Alcohol}

Negative control analyses

The pooled estimate of maternal alcohol consumption in the mutually adjusted model showed some evidence of an association with high risk of $A D H D$ total and inattention symptoms $\left(O R_{A D H D}=1.27\right.$, $\left.95 \% \mathrm{Cl} 1.08,1.49 ; \mathrm{OR}_{\mathrm{INA}}=1.26,95 \% \mathrm{Cl} 1.10,1.44\right)$, but not with hyperactivity symptoms $\left(\mathrm{OR}_{\mathrm{HYP}}=1.13\right.$, $95 \% \mathrm{Cl} 0.87,1.47)$. The strongest associations were observed in ALSPAC and MoBa, in GenR the estimates were in opposite direction for high risk of hyperactivity symptoms. Meta-analysis of paternal alcohol consumption did not show strong evidence of an association with ADHD risk $\left(\mathrm{OR}_{\mathrm{ADHD}}=0.83,95 \% \mathrm{Cl} 0.47,1.48 ; \mathrm{OR}_{\mathrm{HYP}}=0.81,95 \% \mathrm{Cl} 0.53,1.23 ; \mathrm{OR}_{\mathrm{INA}}=0.81,95 \% \mathrm{Cl} 0.52,1.27\right)$, but there was high heterogeneity and confidence intervals were wide. The results across unadjusted, adjusted and mutually adjusted models in each cohort are shown in Supplementary Tables S29-S31.

\section{Sensitivity analyses}

In MoBa, due to the low number of cases, we were not able to report dose-dependent results of the association between maternal prenatal alcohol consumption and high risk of maternal reported offspring ADHD symptoms after adjustment for maternal ADHD (Supplementary Table S32). Additional sensitivity analyses (alcohol use before pregnancy and weekly alcohol use in grams) in ALSPAC and MoBa, and secondary outcome measures in ALSPAC did not find strong evidence for an association between maternal prenatal alcohol use and offspring ADHD risk (Supplementary Tables S33-S37). The results were similar for the analyses of complete cases in each cohort (Supplementary Tables S38-S40).

\section{PRS analyses}

First, in ALSPAC, the PRS for alcohol consumption was associated with prenatal alcohol consumption (Supplementary Table S15 \& S17). However, in MoBa, the PRS for alcohol consumption did not predict alcohol consumption during pregnancy $(\beta=-0.65,95 \% \mathrm{Cl}-0.757,2.055)$, although it was associated with alcohol consumption before pregnancy $(\beta=1.06,95 \% \mathrm{Cl} 0.258,1.859)$ (Supplementary Table S16 \& S18). The alcohol PRS explained 2\% of variance in alcohol phenotype during pregnancy in ALSPAC and $0.7 \%$ variance in alcohol phenotype before pregnancy in MoBa.

Second, the PRS for alcohol consumption was associated with higher maternal education ( $\beta=0.52$, $95 \% \mathrm{Cl} 0.058,0.983)$ and a higher likelihood of having more severe depression symptoms (OR=3.42, 
medRxiv preprint doi: https://doi.org/10.1101/2021.03.25.21254087; this version posted March 26, 2021. The copyright holder for this preprint (which was not certified by peer review) is the author/funder, who has granted medRxiv a license to display the preprint in It is made available under a CC-BY 4.0 International license.

$95 \% \mathrm{Cl} 1.058,11.047$ ) in ALSPAC (Supplementary Table S41). However, no evidence for an association between the PRS for alcohol consumption and confounders was found in MoBa (Supplementary Table S42).

Third, we found no evidence of an association between maternal PRS for alcohol consumption and either high risk of maternal or teacher reported offspring ADHD symptoms in ALSPAC, or with maternal reported ADHD symptoms in MoBa (Supplementary Tables S43-S45).

\section{Caffeine}

Negative control analyses

The pooled estimate of maternal caffeine consumption in the adjusted model showed some evidence of an association only with high risk of offspring $A D H D$ total symptoms $\left(O R_{A D H D}=1.05,95 \% \mathrm{Cl} 1.00\right.$, $1.11 ; \mathrm{OR}_{\mathrm{HYP}}=1.06,95 \% \mathrm{Cl} 0.98,1.14 ; \mathrm{OR}_{\mathrm{INA}}=1.02,95 \% \mathrm{Cl} 0.98,1.07$ ), whereas the meta-analysis of paternal caffeine consumption in ALSPAC and MoBa did not $\left(\mathrm{OR}_{\mathrm{ADHD}}=1.02,95 \% \mathrm{Cl}\right.$ 0.97, 1.07; $\left.\mathrm{OR}_{\mathrm{HYP}}=1.00,95 \% \mathrm{Cl} 0.95,1.06 ; \mathrm{OR}_{\mathrm{INA}}=1.03,95 \% \mathrm{Cl} 0.97,1.09\right)$. Cohort specific results are shown in Supplementary Tables S46-S48.

\section{Sensitivity analyses}

Sensitivity analyses in ALSPAC and MoBa did not find strong evidence for an association between maternal prenatal caffeine consumption and offspring ADHD risk (Supplementary Tables S48-S51). The results were similar in the analyses with complete cases in each cohort (Supplementary Tables S52-S54).

\section{PRS analyses}

First, both the weighted and unweighted PRS for caffeine consumption were associated with total caffeine consumption derived from coffee and tea in ALSPAC and MoBa. The caffeine PRS explained $0.3-0.4 \%$ of variance in caffeine phenotype in ALSPAC and MoBa (Supplementary Tables S15-S18).

Second, we found no strong evidence of an association between the PRS for caffeine consumption and the confounders in ALSPAC or MoBa (Supplementary Tables S55-S56).

Third, we found no strong evidence of an association between maternal PRS for caffeine consumption and either high risk of maternal or teacher reported offspring's ADHD symptoms in ALSPAC or with maternal reported ADHD symptoms in MoBa (Supplementary Tables S57-S59). 
medRxiv preprint doi: https://doi.org/10.1101/2021.03.25.21254087; this version posted March 26, 2021. The copyright holder for this preprint (which was not certified by peer review) is the author/funder, who has granted medRxiv a license to display the preprint in It is made available under a CC-BY 4.0 International license.

Associations between PRS for substance use and participation at age 8 years.

We found evidence of an association between the PRS for lifetime smoking and lower likelihood of returning the questionnaire at age 7-8 years in ALSPAC and $\mathrm{MoBa}\left(\mathrm{OR}_{\mathrm{ALPAC}}=0.49,95 \% \mathrm{Cl} 0.311\right.$, $\left.0.757 ; \mathrm{OR}_{\mathrm{MOBA}}=0.59,95 \% \mathrm{Cl} 0.427,0.801\right)$. Furthermore, in MoBa the PRS for smoking heaviness was associated with higher likelihood of returning the questionnaire $\left(\mathrm{OR}_{\mathrm{MOBA}}=2.10,95 \% \mathrm{Cl} 1.01,4.359\right)$, but a similar association was not observed in ALSPAC (OR $\left.{ }_{\text {ALSPAC }}=0.95 ; 95 \% \mathrm{Cl} 0.561,1.607\right)$ (Supplementary Tables S60-S61). 
medRxiv preprint doi: https://doi.org/10.1101/2021.03.25.21254087; this version posted March 26, 2021. The copyright holder for this preprint (which was not certified by peer review) is the author/funder, who has granted medRxiv a license to display the preprint in perpetuity.
It is made available under a CC-BY 4.0 International license.

\section{Discussion}

We investigated whether maternal smoking, alcohol and caffeine use during pregnancy are likely to be causally associated with offspring ADHD risk. We applied a triangulation approach using negative control and PRS analyses in three longitudinal birth cohorts. Overall, the results did not provide evidence for a potential causal effect between maternal prenatal substance use and offspring ADHD risk although some inconsistencies were observed across the cohorts and instrument used for ADHD assessment.

Our smoking results did not show robust evidence for a causal effect, which is in line with previous findings $(39,47-49)$. Although in GenR and MoBa, we found suggestive evidence for a causal association of maternal prenatal smoking on high risk of maternal reported ADHD symptoms, but when comparing the findings across the cohorts, reporters and questionnaires, the evidence was weak and inconsistent. Additionally, our PRS analyses with lifetime smoking PRS in ALSPAC and MoBa indicated pleiotropic associations which are consistent with recent findings in ALSPAC (50). There is also a large body of evidence showing pleiotropy between smoking, impulsivity and sensationseeking type of personality $(51,52)$ which could confound observed phenotype associations in the present study.

Similarly, our findings on prenatal alcohol and caffeine exposure do not show evidence of a causal effect on offspring ADHD risk. Although a previous study in MoBa found some evidence for a potential causal association of maternal prenatal alcohol consumption when ADHD symptoms were measured with CPRS-R (16), other studies suggest that observed associations between maternal moderate prenatal alcohol consumption and offspring ADHD symptoms may not reflect causal effects $(3,53)$. Our results on caffeine exposure are in line with previous studies which have concluded that there is likely no causal effect of prenatal caffeine consumption on offspring ADHD risk $(6,54,55)$.

Several studies have reported low to moderate parent-teacher agreement on ADHD symptoms assessment $(30,56)$. It has been suggested that parents and teachers may measure different aspects of child's behaviour as ADHD symptoms may be more visible at school which is a more structured environment (30). Furthermore, it has been proposed that parent-teacher ratings may differ because of the informant's perception and individual characteristics (57). It has been shown that mothers with mental health problems or more harsh parenting behaviour overestimate their child's mental health problems $(58,59)$. Given that we observed more associations with maternal report than with 
medRxiv preprint doi: https://doi.org/10.1101/2021.03.25.21254087; this version posted March 26, 2021. The copyright holder for this

preprint (which was not certified by peer review) is the author/funder, who has granted medRxiv a license to display the preprint in

It is made available under a CC-BY 4.0 International license.

teacher report, it is possible that observed associations may be confounded by maternal characteristics.

Besides reporter-related discrepancies, we observed different findings depending on the scales used for ADHD assessment. Previous studies investigating the association between maternal prenatal substance use and offspring ADHD have reported Inconsistent findings depending on which scale was used for ADHD symptoms assessment. For example, a study using the SDQ scale reported association between maternal prenatal smoking and ADHD symptoms in children regardless of the reporter (60). Another study using maternal and teacher reported CPRS-R, CBCL, TRF and combined score of $\mathrm{CBCL} / \mathrm{TRF}$ found some evidence for a potential causal association between maternal prenatal smoking and ADHD symptoms only with maternal reported CPRS-R (61). Similarly, a study on prenatal alcohol exposure found some evidence for a causal association when ADHD symptoms were assessed with maternal reported CPRS-R but not with CBCL (16). Although all the scales for our main outcome measure (DAWBA, CPRS-R, RS-DBD) are based on the Diagnostic and Statistical Manual of Mental Disorders (DSM-IV) criteria for ADHD, we observed inconsistent associations between maternal prenatal substance use and ADHD risk across different scales. It is possible that different scales capture somewhat different aspects of the construct of ADHD.

\section{Strengths and limitations}

The major strength of the current study is the triangulation approach using both observational and genetic analyses, as well as including multiple questionnaires reported by mother and teacher. Using data from three large longitudinal birth cohorts strengthens evidence towards causal interpretation.

However, our study has also limitations. First, outcome assessment varied across the cohorts which may contribute to noise and inconsistent findings. Although all the questionnaires have good psychometric properties, there still may be a risk of measurement error. Second, maternal prenatal substance use was based on self-reports, which most likely lead to underreporting of substance use. Third, our PRS for smoking heaviness and alcohol consumption were calculated based on summary statistics from the latest GWAS which included ALSPAC. However, the contribution of ALSPAC ( 1\%) was small and the risk of bias because of the sample overlap is likely to be minimal (62). Fourth, our PRS analyses were likely underpowered. Compared to the variance explained by each PRS reported in GWAS (smoking heaviness PRS 4\%; alcohol PRS 2.5\%; caffeine PRS 1.3\%), in our sample it was much smaller. Fifth, the sample size in our fully adjusted models were reduced due to missing data in the included confounders which could introduce bias into our estimates. However, we repeated all analyses restricting to individuals in our mutually adjusted models and effect estimates remained 
medRxiv preprint doi: https://doi.org/10.1101/2021.03.25.21254087; this version posted March 26, 2021. The copyright holder for this preprint (which was not certified by peer review) is the author/funder, who has granted medRxiv a license to display the preprint in It is made available under a CC-BY 4.0 International license.

consistent. Sixth, longitudinal cohort studies may suffer from selection bias as socioeconomic and individual characteristics may affect initial and continued participation in the study $(63,64)$. A study in MoBa found that bias due to self-selection and loss to follow-up can influence exposure-outcome associations (65). Another study in ALSPAC showed that common genetic variants of various phenotypes are associated with participation in the study and these associations differ in the sample with full genetic data and more selected subsamples (46). Given that attrition in our study samples was around 50\% and we also observed association between PRS for lifetime smoking and decreased likelihood returning the questionnaire at child's age 7-8 years, it is plausible that our results may be subject to selection bias.

\section{Conclusion}

Combining both observational and genetic analyses from three longitudinal birth cohorts our study did not find support for a causal effect of maternal smoking, alcohol and caffeine consumption during pregnancy on offspring ADHD risk. 
medRxiv preprint doi: https://doi.org/10.1101/2021.03.25.21254087; this version posted March 26, 2021. The copyright holder for this

preprint (which was not certified by peer review) is the author/funder, who has granted medRxiv a license to display the preprint in

It is made available under a CC-BY 4.0 International license.

\section{Declarations of interest}

None.

\section{Acknowledgements}

We are extremely grateful to all the families who took part in this study, the midwives for their help in recruiting them, and the whole ALSPAC team, which includes interviewers, computer and laboratory technicians, clerical workers, research scientists, volunteers, managers, receptionists and nurses. The UK Medical Research Council and Wellcome (Grant ref: 102215/2/13/2) and the University of Bristol provide core support for ALSPAC. A comprehensive list of grants funding is available on the ALSPAC website (http://www.bristol.ac.uk/alspac/external/documents/grantacknowledgements.pdf). GWAS data was generated by Sample Logistics and Genotyping Facilities at Wellcome Sanger Institute and LabCorp (Laboratory Corporation of America) using support from 23andMe.

The Norwegian Mother, Father and Child Cohort Study is supported by the Norwegian Ministry of Health and Care Services and the Ministry of Education and Research. We are grateful to all the participating families in Norway who take part in this on-going cohort study. We thank the Norwegian Institute of Public Health (NIPH) for generating high-quality genomic data. This research is part of the HARVEST collaboration, supported by the Research Council of Norway (NRC) (\#229624). We also thank the NORMENT Centre for providing genotype data, funded by NRC (\#223273), South East Norway Health Authority and KG Jebsen Stiftelsen. Further we thank the Center for Diabetes Research, the University of Bergen for providing genotype data and performing quality control and imputation of the data funded by the ERC AdG project SELECTionPREDISPOSED, Stiftelsen Kristian Gerhard Jebsen, Trond Mohn Foundation, NRC, the Novo Nordisk Foundation, the University of Bergen, and the Western Norway health Authorities (Helse Vest).

The general design of Generation R Study is made possible by financial support from the Erasmus Medical Center, Rotterdam, the Erasmus University Rotterdam, the Netherlands Organization for Health Research and Development (ZonMw), the Netherlands Organisation for Scientific Research (NWO), the Ministry of Health, Welfare and Sport and the Ministry of Youth and Families. The Generation R Study is conducted by the Erasmus Medical Center in close collaboration with the School of Law and Faculty of Social Sciences of the Erasmus University Rotterdam, the Municipal Health Service Rotterdam area, Rotterdam, the Rotterdam Homecare Foundation, Rotterdam and the Stichting Trombosedienst \& Artsenlaboratorium Rijnmond (STAR-MDC), Rotterdam. We 
medRxiv preprint doi: https://doi.org/10.1101/2021.03.25.21254087; this version posted March 26, 2021. The copyright holder for this

preprint (which was not certified by peer review) is the author/funder, who has granted medRxiv a license to display the preprint in

It is made available under a CC-BY 4.0 International license.

gratefully acknowledge the contribution of children and parents, general practitioners, hospitals, midwives and pharmacies in Rotterdam. The generation and management of GWAS genotype data for the Generation R Study were done at the Genetic Laboratory of the Department of Internal Medicine, Erasmus MC, The Netherlands. We would like to thank Karol Estrada, Dr. Tobias A. Knoch, Anis Abuseiris, Luc V. de Zeeuw, and Rob de Graaf, for their help in creating GRIMP, BigGRID, MediGRID, and Services@MediGRID/D-Grid, (funded by the German Bundesministerium fuer Forschung und Technology; grants 01 AK 803 A-H, 01 IG 07015 G) for access to their grid computing resources. We thank Mila Jhamai, Manoushka Ganesh, Pascal Arp, Marijn Verkerk, Lizbeth Herrera and Marjolein Peters for their help in creating, managing and QC of the GWAS database. Also, we thank Karol Estrada for their support in creation and analysis of imputed data.

We would like to thank Sonja Swanson for her valuable ideas when designing the study.

\section{Funding}

This research was performed in the UK Medical Research Council Integrative Epidemiology Unit (grant number MC_UU_00011/7) and also supported by the National Institute for Health Research (NIHR) Bristol Biomedical Research Centre at University Hospitals Bristol NHS Foundation Trust and the University of Bristol. LZ was supported by a UK Medical Research Council fellowship (grant number G0902144). HMS is supported by the European Research Council (Grant ref: 758813 MHINT). The South-Eastern Norway Regional Health Authority supported AH (\#2018059 \&\#2020022). The Norwegian Research Council supported EY (\#262177 \& \#288083), (OAA (RCN\# 273291 \& 223273), TRK (\#274611) and AH (\#274611 \& \#288083).

The views expressed in this publication are those of the authors and not necessarily those of the NHS, the National Institute for Health Research or the Department of Health and Social Care. This research was also conducted as part of the CAPICE (Childhood and Adolescence Psychopathology: unravelling the complex etiology by a large Interdisciplinary Collaboration in Europe) project, funded by the European Union's Horizon 2020 research and innovation programme, Marie Sklodowska Curie Actions - MSCA-ITN-2016 - Innovative Training Networks under grant agreement number 721567. 
medRxiv preprint doi: https://doi.org/10.1101/2021.03.25.21254087; this version posted March 26, 2021. The copyright holder for this preprint (which was not certified by peer review) is the author/funder, who has granted medRxiv a license to display the preprint in

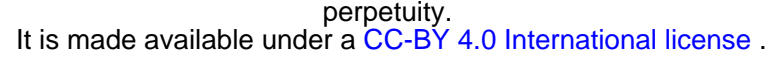

\section{References}

1. Huang L, Wang, Y., Zhang, L., Zheng, Z., Zhu, T., Qu, Y., \& Mu, D. . Maternal Smoking and Attention-Deficit/Hyperactivity Disorder in Offspring: A Meta-analysis. Pediatrics. 2017;14(1):11. 2. He Y, Chen J, Zhu LH, Hua LL, Ke FF. Maternal Smoking During Pregnancy and ADHD: Results From a Systematic Review and Meta-Analysis of Prospective Cohort Studies. J Atten Disord. 2020;24(12):1637-47.

3. Porter MS, Maravilla JC, Betts KS, Alati R. Low-moderate prenatal alcohol exposure and offspring attention-deficit hyperactivity disorder (ADHD): systematic review and meta-analysis. Arch Gynecol Obstet. 2019;300(2):269-77.

4. Pagnin D, Grecco MLZ, Furtado EF. Prenatal alcohol use as a risk for attentiondeficit/hyperactivity disorder. Eur Arch Psy Clin N. 2019;269(6):681-7.

5. Mikkelsen SH, Obel C, Olsen J, Niclasen J, Bech BH. Maternal Caffeine Consumption during Pregnancy and Behavioral Disorders in 11-Year-Old Offspring: A Danish National Birth Cohort Study. J Pediatr-Us. 2017;189:120-+.

6. Del-Ponte B, Santos IS, Tovo-Rodrigues L, Anselmi L, Munhoz TN, Matijasevich A. Caffeine consumption during pregnancy and ADHD at the age of 11 years: a birth cohort study. Bmj Open. 2016;6(12).

7. Easey KE, Dyer ML, Timpson NJ, Munafò MR. Prenatal alcohol exposure and offspring mental health: A systematic review. Drug Alcohol Depend. 2019.

8. Bekkhus M, Skjothaug T, Nordhagen R, Borge AlH. Intrauterine exposure to caffeine and inattention/overactivity in children. Acta Paediatr. 2010;99(6):925-8.

9. Wimberley T, Agerbo E, Horsdal HT, Ottosen C, Brikell I, Als TD, et al. Genetic liability to ADHD and substance use disorders in individuals with ADHD. Addiction. 2020;115(7):1368-77.

10. Leppert B, Havdahl A, Riglin L, Jones HJ, Zheng J, Davey Smith G, et al. Association of Maternal Neurodevelopmental Risk Alleles With Early-Life Exposures. Jama Psychiat. 2019;76(8):83442.

11. Gage SH, Munafò MR, Davey Smith G. Causal Inference in Developmental Origins of Health and Disease (DOHaD) Research. Annu Rev Psychol. 2016;67:567-85.

12. Taylor AE, Carslake D, de Mola CL, Rydell M, Nilsen TIL, Bjorngaard JH, et al. Maternal Smoking in Pregnancy and Offspring Depression: a cross cohort and negative control study. Sci RepUk. 2017;7.

13. Zhu JL, Olsen J, Liew Z, Li J, Niclasen J, Obel C. Parental Smoking During Pregnancy and ADHD in Children: The Danish National Birth Cohort. Pediatrics. 2014;134(2):E382-E8.

14. Rice F, Langley K, Woodford C, Davey Smith G, Thapar A. Identifying the contribution of prenatal risk factors to offspring development and psychopathology: What designs to use and a critique of literature on maternal smoking and stress in pregnancy. Dev Psychopathol.

2018;30(3):1107-28.

15. Skoglund C, Chen Q, D'Onofrio BM, Lichtenstein P, Larsson H. Familial confounding of the association between maternal smoking during pregnancy and ADHD in offspring. J Child Psychol Psychiatry. 2014;55(1):61-8.

16. Eilertsen EM, Gjerde LC, Reichborn-Kjennerud T, Orstavik RE, Knudsen GP, Stoltenberg C, et al. Maternal alcohol use during pregnancy and offspring attention-deficit hyperactivity disorder (ADHD): a prospective sibling control study. International Journal of Epidemiology. 2017;46(5):163340.

17. Lund IO, Eilertsen EM, Gjerde LC, Roysamb E, Wood M, Reichborn-Kjennerud T, et al. Is the association between maternal alcohol consumption in pregnancy and pre-school child behavioural and emotional problems causal? Multiple approaches for controlling unmeasured confounding. Addiction. 2019;114(6):1004-14.

18. Lawlor DA, Harbord RM, Sterne JAC, Timpson N, Davey Smith G. Mendelian randomization: Using genes as instruments for making causal inferences in epidemiology. Stat Med.

2008;27(8):1133-63. 
medRxiv preprint doi: https://doi.org/10.1101/2021.03.25.21254087; this version posted March 26, 2021. The copyright holder for this preprint (which was not certified by peer review) is the author/funder, who has granted medRxiv a license to display the preprint in

It is made available under a CC-BY 4.0 International license .

19. Davies NM, Holmes MV, Smith GD. Reading Mendelian randomisation studies: a guide, glossary, and checklist for clinicians. Bmj-Brit Med J. 2018;362.

20. Munafò MR, Davey Smith G. Robust research needs many lines of evidence. Nature. 2018;553(7689):399-401.

21. Lawlor DA, Tilling K, Davey Smith G. Triangulation in aetiological epidemiology. Int J Epidemiol. 2016;45(6):1866-86.

22. Fraser A, Macdonald-Wallis C, Tilling K, Boyd A, Golding J, Smith GD, et al. Cohort Profile: The Avon Longitudinal Study of Parents and Children: ALSPAC mothers cohort. International Journal of Epidemiology. 2013;42(1):97-110.

23. Boyd A, Golding J, Macleod J, Lawlor DA, Fraser A, Henderson J, et al. Cohort Profile: The 'Children of the 90s'-the index offspring of the Avon Longitudinal Study of Parents and Children. International Journal of Epidemiology. 2013;42(1):111-27.

24. Northstone K, Lewcock M, Groom A, Boyd A, Macleod J, Timpson N, et al. The Avon Longitudinal Study of Parents and Children (ALSPAC): an update on the enrolled sample of index children in 2019. Wellcome Open Res. 2019;4:51.

25. Kooijman MN, Kruithof CJ, van Duijn CM, Duijts L, Franco OH, van IJzendoorn MH, et al. The Generation R Study: design and cohort update 2017. Eur J Epidemiol. 2016;31(12):1243-64.

26. Magnus P, Birke C, Vejrup K, Haugan A, Alsaker E, Daltveit AK, et al. Cohort Profile Update: The Norwegian Mother and Child Cohort Study (MoBa). International Journal of Epidemiology. 2016;45(2):382-8.

27. Gard AM, Owens EB, Hinshaw SP. Prenatal Smoke Exposure Predicts Hyperactive/Impulsive but Not Inattentive ADHD Symptoms in Adolescent and Young Adult Girls. Infant Child Dev. 2016;25(4):339-51.

28. Langley K, Holmans PA, van den Bree MBM, Thapar A. Effects of low birth weight, maternal smoking in pregnancy and social class on the phenotypic manifestation of Attention Deficit Hyperactivity Disorder and associated antisocial behaviour: investigation in a clinical sample. Bmc Psychiatry. 2007;7.

29. Aylward GP, Stancin T. Screening and assessment tools. Measurement and psychometric considerations. Developmental Behavioral PediatricsEvidence and Practice. Philadelphia: Elsiver; 2008. p. 123-9.

30. Narad ME, Garner AA, Peugh JL, Tamm L, Antonini TN, Kingery KM, et al. Parent-Teacher Agreement on ADHD Symptoms Across Development. Psychol Assessment. 2015;27(1):239-48.

31. Liu MZ, Jiang Y, Wedow R, Li Y, Brazel DM, Chen F, et al. Association studies of up to 1.2 million individuals yield new insights into the genetic etiology of tobacco and alcohol use. Nat Genet. 2019;51(2):237-+.

32. Cornelis MC, Byrne EM, Esko T, Nalls MA, Ganna A, Paynter N, et al. Genome-wide metaanalysis identifies six novel loci associated with habitual coffee consumption. Mol Psychiatr. 2015;20(5):647-56.

33. StataCorp. Stata Statistical Software: Release 15. College Station, TX: StataCorp LLC.; 2017.

34. StataCorp. Stata Statistical Software: Release 16. College Station, TX: StataCorp LLC.; 2019.

35. Haan E, Sallis H, Zuccolo L, Swanson J, Ystrom E, Havdahl A, et al. Maternal and paternal comparison and Mendelian Randomization analyses of alcohol, tobacco and caffeine use in pregnancy and ADHD in offspring. Open Science Framework. 2019.

36. Kovess V, Keyes KM, Hamilton A, Pez O, Bitfoi A, Koc C, et al. Maternal smoking and offspring inattention and hyperactivity: results from a cross-national European survey. Eur Child Adoles Psy. 2015;24(8):919-29.

37. Gilman SE, Gardener H, Buka SL. Maternal smoking during pregnancy and children's cognitive and physical development: a causal risk factor? Am J Epidemiol. 2008;168(5):522-31.

38. Russell AE, Ford T, Russell G. Socioeconomic Associations with ADHD: Findings from a Mediation Analysis. Plos One. 2015;10(6). 
medRxiv preprint doi: https://doi.org/10.1101/2021.03.25.21254087; this version posted March 26, 2021. The copyright holder for this preprint (which was not certified by peer review) is the author/funder, who has granted medRxiv a license to display the preprint in

It is made available under a CC-BY 4.0 International license .

39. Langley K, Heron J, Davey Smith G, Thapar A. Maternal and Paternal Smoking During Pregnancy and Risk of ADHD Symptoms in Offspring: Testing for Intrauterine Effects. American Journal of Epidemiology. 2012;176(3):261-8.

40. Sagiv SK, Epstein JN, Bellinger DC, Korrick SA. Pre- and postnatal risk factors for ADHD in a nonclinical pediatric population. J Atten Disord. 2013;17(1):47-57.

41. Grant JD, Heath AC, Bucholz KK, Madden PAF, Agrawal A, Statham DJ, et al. Spousal concordance for alcohol dependence: Evidence for assortative mating or spousal interaction effects? Alcohol Clin Exp Res. 2007;31(5):717-28.

42. Howe LJ, Lawson DJ, Davies NM, St Pourcain B, Lewis SJ, Davey Smith G, et al. Genetic evidence for assortative mating on alcohol consumption in the UK Biobank. Nat Commun. 2019;10.

43. Madley-Dowd P, Rai D, Zammit S, Heron J. Simulations and directed acyclic graphs explained why assortative mating biases the prenatal negative control design. J Clin Epidemiol. 2020;118:9-17.

44. Shi JX, Park JH, Duan JB, Berndt ST, Moy W, Yu K, et al. Winner's Curse Correction and Variable Thresholding Improve Performance of Polygenic Risk Modeling Based on Genome-Wide Association Study Summary-Level Data. Plos Genet. 2016;12(12).

45. Wootton RE, Richmond RC, Stuijfzand BG, Lawn RB, Sallis HM, Taylor GMJ, et al. Evidence for causal effects of lifetime smoking on risk for depression and schizophrenia: a Mendelian randomisation study. Psychol Med. 2020;50(14):2435-43.

46. Taylor AE, Jones HJ, Sallis H, Euesden J, Stergiakouli E, Davies NM, et al. Exploring the association of genetic factors with participation in the Avon Longitudinal Study of Parents and Children. International Journal of Epidemiology. 2018;47(4):1207-16.

47. Gustavson K, Ystrom E, Stoltenberg C, Susser E, Suren P, Magnus P, et al. Smoking in Pregnancy and Child ADHD. Pediatrics. 2017;139(2).

48. Roza SJ, Verhulst FC, Jaddoe VW, Steegers EA, Mackenbach JP, Hofman A, et al. Maternal smoking during pregnancy and child behaviour problems: the Generation R Study. Int J Epidemiol. 2009;38(3):680-9.

49. Pingault J-B, Barkhuizen W, Wang B, Hannigan L, Eilertsen EM, Andreassen OA, et al. Identifying intergenerational risk factors for ADHD symptoms using polygenic scores in the Norwegian Mother, Father and Child Cohort. medRxiv. 2021.

50. Schellhas L, Haan E, Easey KE, Wootton R, Sallis H, Sharp GC, et al. Maternal and child genetic liability for smoking and caffeine consumption and child mental health: An intergenerational polygenic risk score analysis in the ALSPAC cohort. medRxiv. 2020.

51. Harrison R, Munafò MR, Davey Smith G, Wootton RE. Examining the effect of smoking on suicidal ideation and attempts: triangulation of epidemiological approaches. Brit J Psychiat. 2020;217(6):701-7.

52. Khouja JN, Wootton RE, Taylor AE, Davey Smith G, Munafò MR. Association of genetic liability to smoking initiation with e-cigarette use in young adults: A cohort study. PLoS Med. 2021;18(3):e1003555.

53. D'Onofrio BM, Van Hulle CA, Waldman ID, Rodgers JL, Rathouz PJ, Lahey BB. Causal inferences regarding prenatal alcohol exposure and childhood externalizing problems. Arch Gen Psychiat. 2007;64(11):1296-304.

54. Loomans EM, Hofland L, Van der Stelt O, Van der Wal MF, Koot HM, Van den Bergh BRH, et al. Caffeine Intake During Pregnancy and Risk of Problem Behavior in 5- to 6-Year-Old Children. Pediatrics. 2012;130(2):E305-E13.

55. Berglundh S, Vollrath M, Brantsaeter AL, Brandlistuen R, Sole-Navais $P$, Jacobsson B, et al. Maternal caffeine intake during pregnancy and child neurodevelopment up to eight years of ageResults from the Norwegian Mother, Father and Child Cohort Study. Eur J Nutr. 2020.

56. Sollie H, Larsson B, Morch WT. Comparison of Mother, Father, and Teacher Reports of ADHD Core Symptoms in a Sample of Child Psychiatric Outpatients. J Atten Disord. 2013;17(8):699-710.

57. Amador-Campos JA, Forns-Santacana M, Guardia-Olmos J, Pero-Cebollero M. DSM-IV attention deficit hyperactivity disorder symptoms: Agreement between informants in prevalence and factor structure at different ages. J Psychopathol Behav. 2006;28(1):23-32. 
medRxiv preprint doi: https://doi.org/10.1101/2021.03.25.21254087; this version posted March 26, 2021. The copyright holder for this preprint (which was not certified by peer review) is the author/funder, who has granted medRxiv a license to display the preprint in

perpetuity.
It is made available under a CC-BY 4.0 International license .

58. Najman JM, Williams GM, Nikles J, Spence S, Bor W, O'Callaghan M, et al. Bias influencing maternal reports of child behaviour and emotional state. Soc Psych Psych Epid. 2001;36(4):186-94. 59. Lavigne JV, Dahl KP, Gouze KR, LeBailly SA, Hopkins J. Multi-Domain Predictors of Oppositional Defiant Disorder Symptoms in Preschool Children: Cross-Informant Differences. Child Psychiat Hum D. 2015;46(2):308-19.

60. Sutin AR, Flynn HA, Terracciano A. Maternal cigarette smoking during pregnancy and the trajectory of externalizing and internalizing symptoms across childhood: Similarities and differences across parent, teacher, and self reports. J Psychiatr Res. 2017;91:145-8.

61. Knopik VS, Marceau K, Bidwell LC, Palmer RHC, Smith TF, Todorov A, et al. Smoking During Pregnancy and ADHD Risk: A Genetically Informed, Multiple-Rater Approach. Am J Med Genet B. 2016;171(7):971-81.

62. Burgess S, Davies NM, Thompson SG. Bias due to participant overlap in two-sample Mendelian randomization. Genet Epidemiol. 2016;40(7):597-608.

63. Nohr EA, Frydenberg M, Henriksen TB, Olsen J. Does low participation in cohort studies induce bias? Epidemiology. 2006;17(4):413-8.

64. Launes J, Hokkanen L, Laasonen M, Tuulio-Henriksson A, Virta M, Lipsanen J, et al. Attrition in a 30-year follow-up of a perinatal birth risk cohort: factors change with age. Peerj. 2014;2.

65. Biele G, Gustavson K, Czajkowski NO, Nilsen RM, Reichborn-Kjennerud T, Magnus PM, et al. Bias from self selection and loss to follow-up in prospective cohort studies. Eur J Epidemiol. 2019;34(10):927-38 . 


\section{Table 1. Overview of cohorts}

\begin{tabular}{|c|c|c|c|c|c|c|c|c|c|}
\hline \multirow[b]{2}{*}{ Characteristics } & \multicolumn{3}{|c|}{ ALSPAC } & \multicolumn{3}{|c|}{ GenR } & \multicolumn{3}{|c|}{ MoBA } \\
\hline & Mothers & Fathers & Children & Mothers & Father & Children & Mothers & Fathers & Children \\
\hline \multirow{3}{*}{ Age } & 7,886 & 6,374 & 7,850 & 3,849 & 2,672 & 3,849 & 43,364 & 35,376 & 43,512 \\
\hline & (15-44 years) & (16-75 years) & (7.5-9 years) & (15-46 years) & (17-58 years) & (7.5-11 years) & (16-46 years) & (17-60 years) & (8-10 years) \\
\hline \multirow{2}{*}{\multicolumn{10}{|c|}{ Ethnicity* }} \\
\hline & & & & & & & & & \\
\hline European & $7,500(98 \%)$ & $6,180(97 \%)$ & & $2,715(71 \%)$ & $2,073(78 \%)$ & & $41,196(95 \%)$ & $33,607(95 \%)$ & \\
\hline Non-European & $131(2 \%)$ & $157(3 \%)$ & & $1,110(29 \%)$ & $598(22 \%)$ & & $2168(5 \%)$ & $1,769(5 \%)$ & \\
\hline Marital status & \multirow{2}{*}{\multicolumn{3}{|c|}{$6,267(81 \%)$}} & \multirow{2}{*}{\multicolumn{3}{|c|}{$1,894(51 \%)$}} & \multirow{2}{*}{\multicolumn{2}{|c|}{21,699 (51\%) }} & \\
\hline Married & & & & & & & & & \\
\hline Cohabiting & \multirow{2}{*}{\multicolumn{3}{|c|}{-}} & \multicolumn{3}{|c|}{$1,452(40 \%)$} & \multicolumn{2}{|c|}{$19,949(46 \%)$} & \\
\hline Single & & & & \multirow{2}{*}{\multicolumn{2}{|c|}{$330(9 \%)$}} & & \multicolumn{2}{|c|}{$724(2 \%)$} & \\
\hline Other & \multicolumn{2}{|c|}{$\begin{array}{c}381(5 \%) \\
1,079(14 \%)\end{array}$} & & & & & & & \\
\hline \multicolumn{10}{|l|}{ Education } \\
\hline Primary & $1,094(14 \%)$ & $1,092(20 \%)$ & & $232(6 \%)$ & $132(5 \%)$ & & $587(1 \%)$ & $1,088(3 \%)$ & \\
\hline Secondary & $5,342(70 \%)$ & $3,674(58 \%)$ & & $1,444(40 \%)$ & $921(38 \%)$ & & $10,859(27 \%)$ & $13,961(41 \%)$ & \\
\hline Higher & $1,219(16 \%)$ & $1,475(22 \%)$ & & $1,968(54 \%)$ & $1,366(57 \%)$ & & $29,506(72 \%)$ & $19,190(56 \%)$ & \\
\hline \multicolumn{10}{|l|}{ Financial difficulties** } \\
\hline Yes & \multicolumn{2}{|c|}{$4,448(60 \%)$} & & \multicolumn{2}{|c|}{$463(15 \%)$} & & \multicolumn{2}{|c|}{$5888(14 \%)$} & \\
\hline Mental health (screened positive)*** & & & & & & & & & \\
\hline Depression & $811(11 \%)$ & $170(3 \%)$ & & $213(7 \%)$ & $62(3 \%)$ & & $2,623(6 \%)$ & $1,044(3 \%)$ & \\
\hline Anxiety & $1,010(14 \%)$ & $539(10 \%)$ & & $267(9 \%)$ & $144(6 \%)$ & & & & \\
\hline \multicolumn{10}{|l|}{ Parental ADHD*** } \\
\hline Screened positive & & & & & & & $877(3 \%)$ & $727(5 \%)$ & \\
\hline Smoking**** & & & & & & & & & \\
\hline No cigarettes & $6,256(81 \%)$ & 3,521 (70\%) & & 2,471 (79\%) & $1,412(59 \%)$ & & $40,335(94 \%)$ & $27,715(79 \%)$ & \\
\hline 1-4 cigarettes & $372(5 \%)$ & $258(5 \%)$ & & $358(11 \%)$ & $387(16 \%)$ & & $1,284(3 \%)$ & $3,321(9 \%)$ & \\
\hline 5-9 cigarettes & $367(5 \%)$ & $205(4 \%)$ & & $159(5 \%)$ & $166(7 \%)$ & & $664(2 \%)$ & $908(3 \%)$ & \\
\hline$>10$ cigarettes & $736(9 \%)$ & $1,050(21 \%)$ & & $128(4 \%)$ & $416(18 \%)$ & & $457(1 \%)$ & $3,005(9 \%)$ & \\
\hline Alcohol consumption $* * * *$ & & & & & & & & & \\
\hline None & $3,411(44 \%)$ & $176(3 \%)$ & & 1,521 (49\%) & $279(12 \%)$ & & $34,645(88 \%)$ & $1,966(15 \%)$ & \\
\hline$<1$ unit per week & $3,119(40 \%)$ & $1,180(23 \%)$ & & $933(30 \%)$ & $311(13 \%)$ & & $4,464(11.5 \%)$ & $3,530(27 \%)$ & \\
\hline $1-6$ units per week & $1,046(14 \%)$ & $2,762(53 \%)$ & & $576(18 \%)$ & $1,166(49 \%)$ & & 165 (0.44\%) & $4,785(36 \%)$ & \\
\hline$>1$ unit per day & $135(2 \%)$ & $1,095(21 \%)$ & & $97(3 \%)$ & $617(26 \%)$ & & $3(0.01 \%)$ & $2,889(22 \%)$ & \\
\hline Caffeine consumption $* * * * *$ & & & & & & & & & \\
\hline $0-49 \mathrm{mg}$ per day & $1,026(13 \%)$ & $183(3 \%)$ & & $499(19 \%)$ & $* * * *$ & & $27,424(63 \%)$ & $3,529(22 \%)$ & \\
\hline 50-199mg per day & 3,149 (41\%) & $660(13 \%)$ & & $1,251(48 \%)$ & & & $13,192(30 \%)$ & $5,661(36 \%)$ & \\
\hline 200-299mg per day & $1,871(25 \%)$ & $833(16 \%)$ & & $443(17 \%)$ & & & $1,907(5 \%)$ & $4,661(30 \%)$ & \\
\hline$>300 \mathrm{mg}$ per day & $1,634(21 \%)$ & $3,593(68 \%)$ & & $420(16 \%)$ & & & $917(2 \%)$ & $1,931(12 \%)$ & \\
\hline Offspring gender & & & & & & & & & \\
\hline Male & & & 4,054 (51\%) & & & $1,911(50 \%)$ & & & $22,115(51 \%)$ \\
\hline Female & & & $3,859(49 \%)$ & & & $1,938(50 \%)$ & & & 21,249 (49\%) \\
\hline Parity & & & & & & & & & \\
\hline 1 & & & $3,533(46 \%)$ & & & $2,278(61 \%)$ & & & $19,788(46 \%)$ \\
\hline 2 & & & 2,735 (36\%) & & & $1,019(28 \%)$ & & & 15,339 (35\%) \\
\hline 3 & & & $1,017(13 \%)$ & & & $309(8 \%)$ & & & $6,522(15 \%)$ \\
\hline $4+$ & & & $361(5 \%)$ & & & $100(3 \%)$ & & & $1,715(4 \%)$ \\
\hline
\end{tabular}

(1)

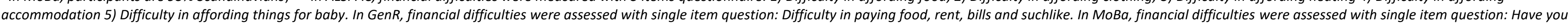
experienced financial problems?; *** In ALSPAC, maternal and paternal depression symptoms were measured using Edinburgh Postnatal Depressions Scale (EPDS; cut-off score >12) and anxiety symptoms with the anxiety sub-scale of the Crown-Crisp

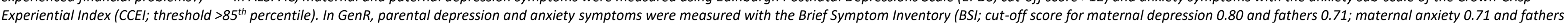

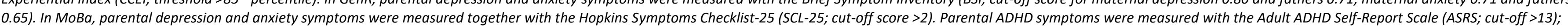

$* * * *$ consumption during the $1^{\text {st }}$ pregnancy trimester; $* * * *$ not assessed 
medRxiv preprint doi: https://doi.org/10.1101/2021.03.25.21254087; this version posted March 26, 2021. The copyright holder for this preprint (which was not certified by peer review) is the author/funder, who has granted medRxiv a license to display the preprint in perpetuity.

It is made available under a CC-BY 4.0 International license .

\section{Figure 1. Study design}

a) Negative control analysis

Confounding

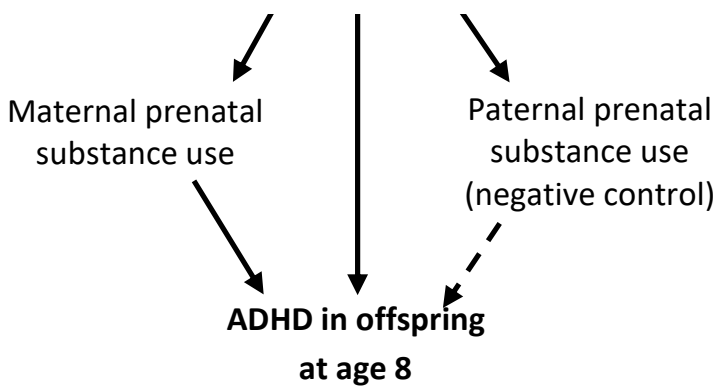

b) Polygenic risk score analysis

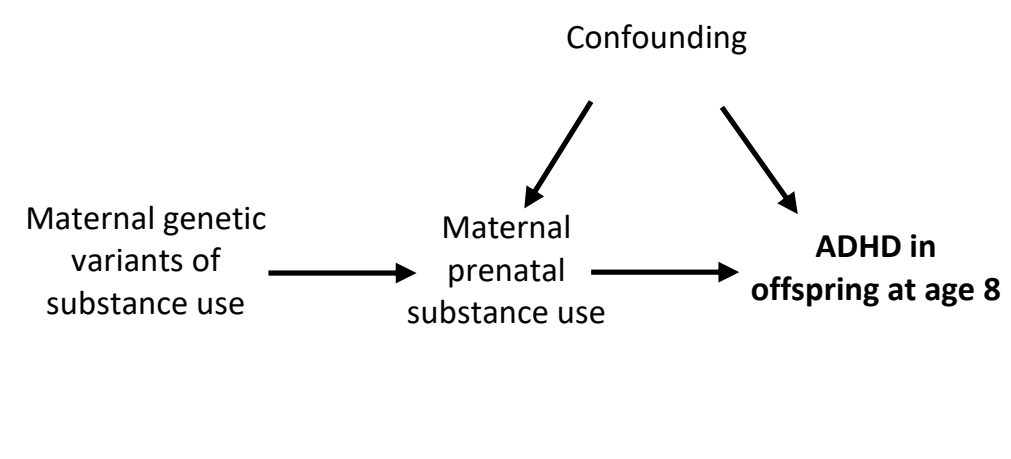

Note: a) The dashed arrow represents the negative control analysis. Assumption includes: the same confounders influence maternal and paternal prenatal substance use and offspring ADHD, a causal prenatal (intrauterine) effect only exists for maternal prenatal substance use. b) Polygenic risk score analysis was conducted with maternal genetic variants as proxies for prenatal smoking, alcohol and caffeine consumption (3 separate analyses, with polygenic risk scores specific to the substance used). 
medRxiv preprint doi: https://doi.org/10.1101/2021.03.25.21254087; this version posted March 26, 2021. The copyright holder for this preprint (which was not certified by peer review) is the author/funder, who has granted medRxiv a license to display the preprint in

perpetuity.
It is made available under a CC-BY 4.0 International license .

Figure 2. Meta-analysis of maternal and paternal prenatal smoking, alcohol and caffeine consumption across the cohorts

a)

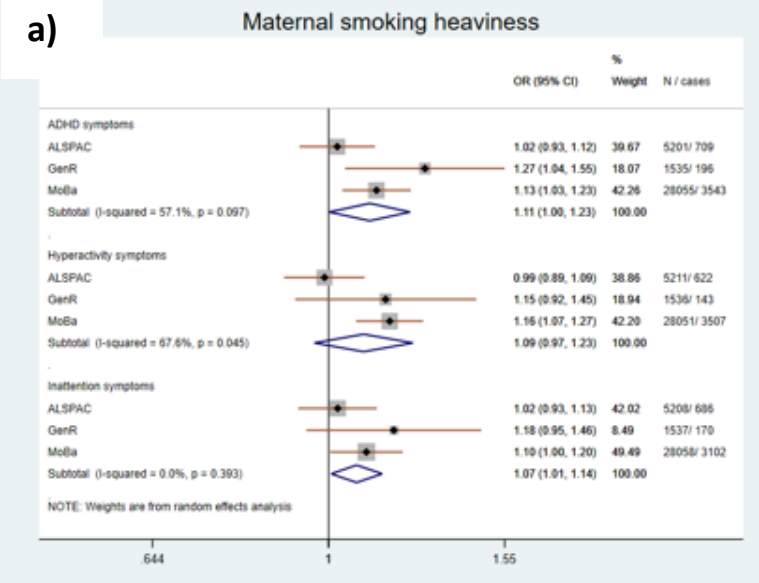

b)

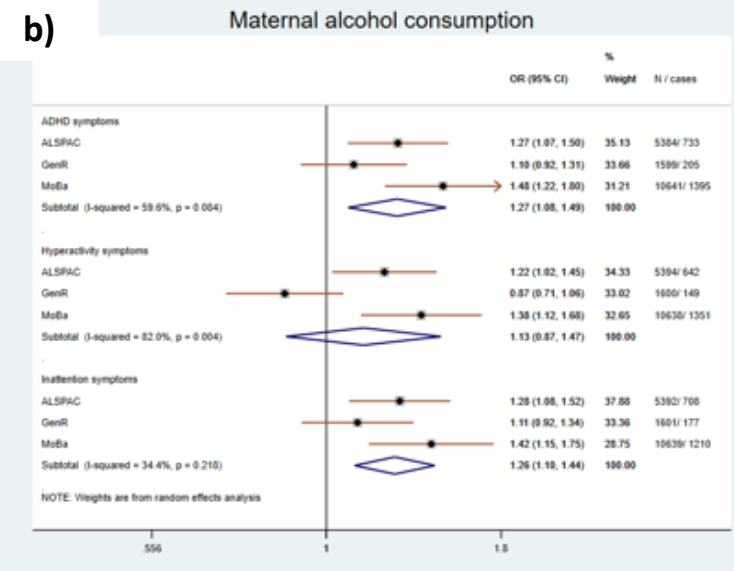

c)

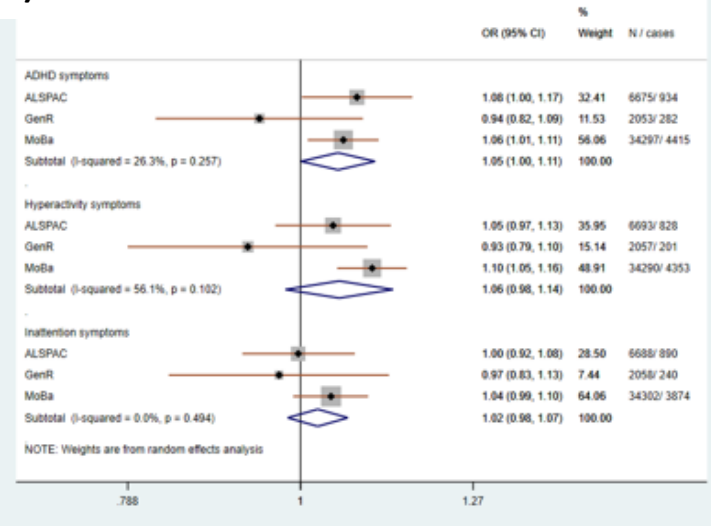

Paternal smoking heaviness

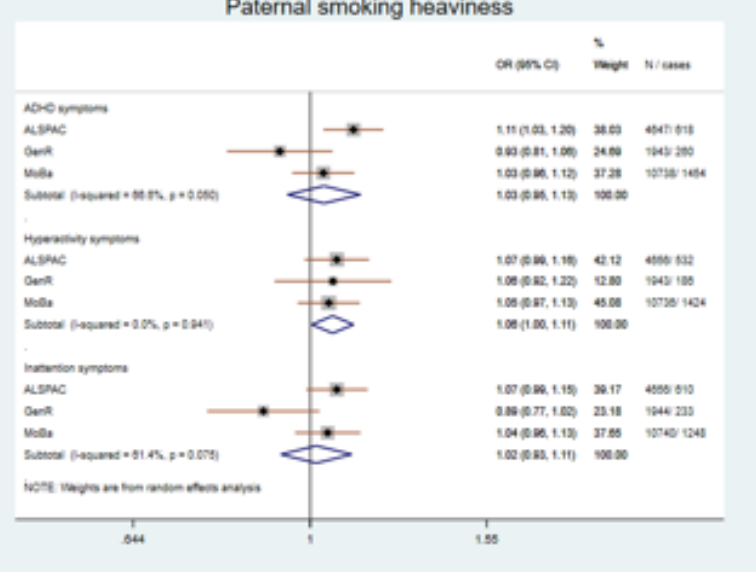

Paternal alcohol consumption

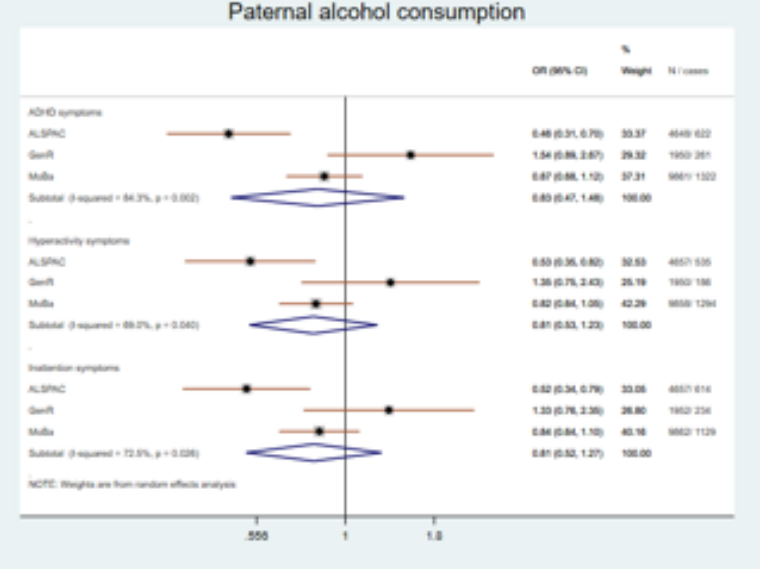

Paternal caffeine consumption

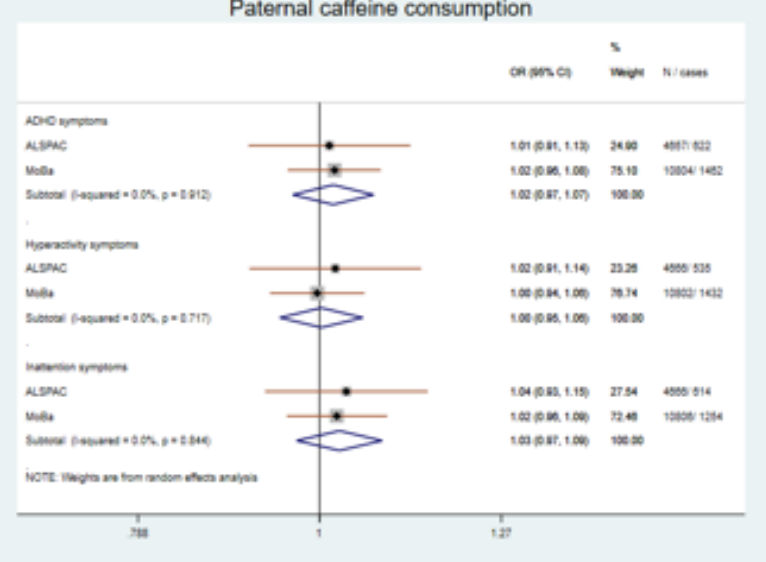

Note: Meta-analysis of smoking (a) and alcohol consumption (b) are based on mutually adjusted model. Metaanalysis of caffeine consumption (c) is based on adjusted model, because paternal caffeine consumption was not assessed in GenR. Heterogeneity between the cohorts is shown by computing $I^{2}$ (see Methods and Supplementary Table S1 for more details). 